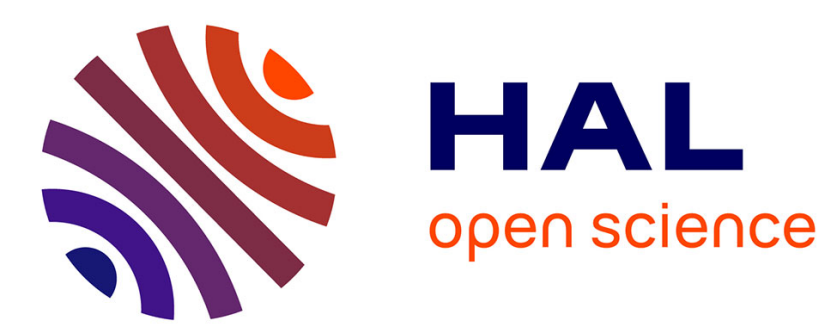

\title{
Scanning tunneling microscopy of locally derivatized self-assembled organic monolayers
}

N. Battaglini, Hubert Klein, Philippe Dumas, C. Moustrou, A. Samat

\section{To cite this version:}

N. Battaglini, Hubert Klein, Philippe Dumas, C. Moustrou, A. Samat. Scanning tunneling microscopy of locally derivatized self-assembled organic monolayers. Applied Surface Science, 2003, 212-213, pp.481 - 484. 10.1016/S0169-4332(03)00144-2 . hal-01770311

\section{HAL Id: hal-01770311 \\ https://hal-amu.archives-ouvertes.fr/hal-01770311}

Submitted on 4 May 2018

HAL is a multi-disciplinary open access archive for the deposit and dissemination of scientific research documents, whether they are published or not. The documents may come from teaching and research institutions in France or abroad, or from public or private research centers.
L'archive ouverte pluridisciplinaire HAL, est destinée au dépôt et à la diffusion de documents scientifiques de niveau recherche, publiés ou non, émanant des établissements d'enseignement et de recherche français ou étrangers, des laboratoires publics ou privés. 


\title{
Scanning tunneling microscopy of locally derivatized self-assembled organic monolayers
}

\author{
N. Battaglini ${ }^{a}$, H. Klein ${ }^{\text {a,* }}, P h$. Dumas ${ }^{a}$, \\ C. Moustrou ${ }^{\mathrm{b}}$, A. Samat ${ }^{\mathrm{b}}$ \\ ${ }^{\mathrm{a}}$ GPEC UMR CNRS 6631, Faculté des Sciences de Luminy, F-13288 Marseille Cedex 9, France \\ ${ }^{\mathrm{b}}$ LCMOM UMR CNRS 6114, Faculté des Sciences de Luminy, F-13288 Marseille Cedex 9, France
}

\begin{abstract}
We report on the scanning tunneling microscopy (STM) study of self assembled monolayers (SAMs) on Au(1 1 1). SAMs consist of mono and bi-component alkylthiol of various chemical functionnalizations. Such systems give the opportunity to elaborate surfaces with tuned chemical properties. We will show our first results concerning the selective grafting of conjugated organic groups on a bi-component SAM composed of methyl and alcohol terminated molecules.
\end{abstract}

PACS: 81-07.Nb; 81-16.Dn; 68-37.Ef

Keywords: Self-assembly; Scanning tunneling microscopy; Surface chemistry

\section{Introduction}

Self-assembled monolayers (SAMs) are molecular monolayers chemically bonded to a solid substrate. They are spontaneously formed during immersion of a substrate in a solution of surfactant molecules. Among the many systems that can lead to SAMs [1,2], $n$ alkylthiols $\left(\mathrm{CH}_{3}-\left(\mathrm{CH}_{2}\right)_{(n-1)}-\mathrm{SH}\right)$ on gold are the most studied ones. Indeed, $n$-alkylthiol SAMs on $\mathrm{Au}\left(\begin{array}{lll}1 & 1 & 1\end{array}\right)$ are the prototype SAM exhibiting a good crystalline quality and a long term chemical stability. Scanning tunneling microscopy (STM) is a first class tool for surface analysis at the nanometric scale and is thus suitable for SAMs studies. It was successfully applied

\footnotetext{
* Corresponding author.

E-mail address: klein@gpec.univ-mrs.fr (H. Klein).
}

to organic alkylthiol systems on gold down to molecular resolution [3]. It is possible to chemically derivatize SAMs in order to build new structures with novel properties [4]. These processes lead to mixed SAMs exhibiting domains of distinct chemical properties. Moreover, SAM two-dimensional (2D) crystal can be used as isolated molecule holder, e.g. for the study of the electronic properties of individual molecules $[5,6]$.

In this study, we report about the elaboration and STM observations of mixed SAMs (decanethiol, and 11-mercapto1-undecanol). We then propose a new versatile method to produce chemically derivatized SAMs. This method consists in grafting various chemical groups on hydroxyl terminated molecules, via a mild esterification (Hassner) reaction. We illustrate this method by reporting the observation of isolated phenyl groups chemically grafted to SAMs. 


\section{Experimental}

\subsection{SAMs elaboration}

$N$-alkylthiol SAMs are grafted onto Au(1 111$)$ thin films evaporated on mica. SAMs elaboration is achieved by immersing fresh gold substrates in $10^{-3} \mathrm{M}$ solutions of alkylthiols in dichloromethane for $12 \mathrm{~h}$. Samples are then extensively rinsed successively with ethanol and dichloromethane and dried under a nitrogen flow prior STM imaging. The detailed procedure of sample preparation is described elsewhere [7]. We have prepared mixed SAMs by immersing gold surfaces in solutions containing both decanethiol $\left(\mathrm{CH}_{3}\left(\mathrm{CH}_{2}\right)_{9} \mathrm{SH}\right)$ and 11-mercapto1-undecanol $\left(\mathrm{HS}\left(\mathrm{CH}_{2}\right)_{10} \mathrm{CH}_{2} \mathrm{OH}\right)$ with ratios varying from 3 to $30 \%$ of mercapto-undecanol for $12 \mathrm{~h}$ at $300 \mathrm{~K}$.

\subsection{Chemical bonding on top of SAMs}

The grafting of carboxylic acid onto hydroxyl-prefunctionnalized surface is achieved by a mild esterification method [8]. The surface is immersed into a solution of carboxylic acid (1 M equivalent, hereafter eq.), DCC ( $N, N$-dicyclohexylcarbodiimide, 1.1 eq.) and 4-pyrrolidinopyridine $\left(10^{-2}\right.$ eq.) in dichloromethane $(100 \mathrm{ml})$ for $2 \mathrm{~h}$. The reaction occurs at room temperature, under neutral conditions. It is noteworthy that the usual esterification reactions proceed in the presence of catalytic amounts of strong acids (sulfuric acid, $p$-toluenesulfonic acid ...). In our case, these drastic experimental conditions cannot be used while the SAMs are damaged. Our method is versatile, because starting from a hydroxyl-prefunctionnalized substrate, a wide range of molecules adequately functionnalized by a carboxylic function can be locally grafted. The results presented here deal with benzoic acid $\left(\mathrm{C}_{6} \mathrm{H}_{5} \mathrm{COOH}\right)$ reacting with isolated 11-mercapto1-undecanol.

\subsection{STM imaging}

STM imaging in constant current mode is performed in ambient conditions. The experimental setup used for this work allows regulation currents down to $0.5 \mathrm{pA}$ (1 kHz BW). STM tips are prepared by cutting $0.25 \mathrm{~mm}$ diameter Pt:Ir (80:20) wires. Due to the strong insulating nature of alkylthiol molecules (saturated carbon chains with a HOMO/LUMO gap around $9 \mathrm{eV}$ [9]), non-intrusive STM imaging on alkylthiol films is only feasible using a tunnel resistance in the $T \Omega$ range. We have shown earlier that in these conditions, the STM tip flies over the organic layer at an altitude around $2 \AA$ [10].

\section{STM observation of chemically functionnalized SAMs}

\subsection{STM imaging of mixed SAMs substrates}

We started by observing surfaces of unreacted SAMs composed of decanethiol and mercapto-undecanol. Fig. 1 presents typical results obtained on SAMs
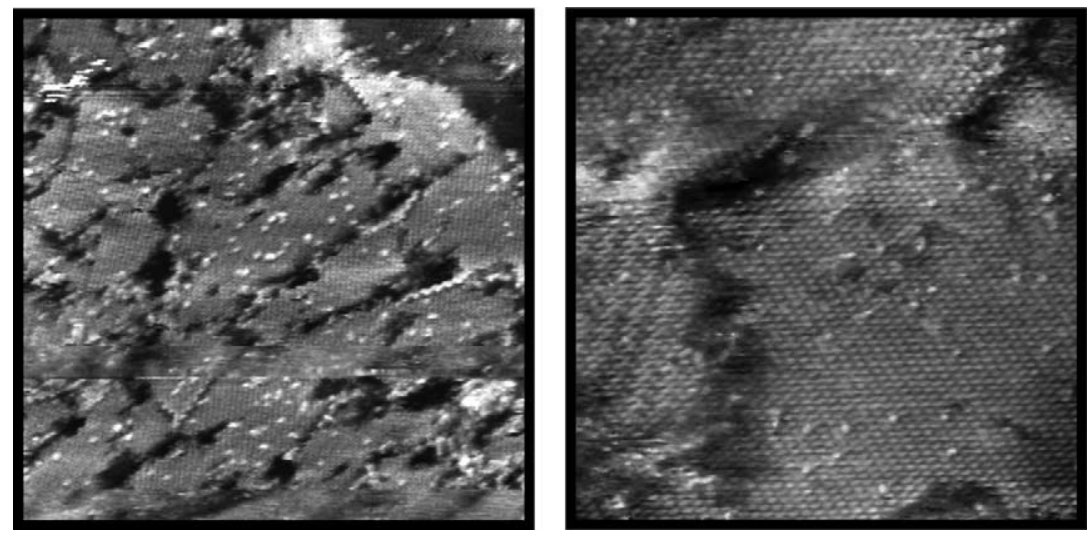

Fig. 1. STM images of mixed SAMs composed of decanethiol and 11-mercapto1-undecanol. Left: scan size $512 \AA \times 512 \AA, V_{\mathrm{t}}=-900 \mathrm{mV}$, $I_{\mathrm{t}}=3$ pA. Right: scan size $256 \AA \times 256 \AA, V_{\mathrm{t}}=-900 \mathrm{mV}, I_{\mathrm{t}}=3 \mathrm{pA}$. On both images, hydroxyl terminated molecules appear as bright features. We have estimated the hydroxyl surface coverage to $2 \%$. 


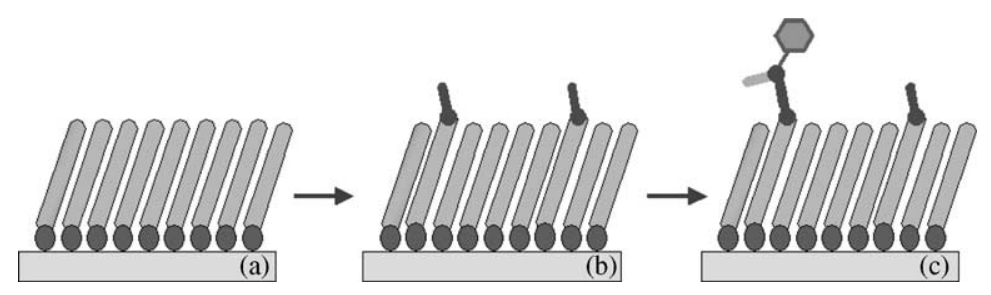

Fig. 2. Schematic of the three steps necessary for the nanografting of isolated molecules. (a) Elaboration of a decanethiol SAM; (b) insertion of mercapto-undecanol; (c) Hassner reaction.

prepared from a solution containing $10 \%$ of mercaptoundecanol. There is a clear contrast between methyl and hydroxyl terminated alkylthiols. This STM contrast is attributed to both the different length of the carbon backbones of the molecules [10], and to the influence of the headgroup [11,12]. We have also investigated the influence of the ratio mercapto-undecanol/decanethiol in solution on the hydroxyl surface coverage. The hydroxyl surface coverage increases with the proportion of mercapto-undecanol in solution [4]. In our experimental conditions, the proportion of hydroxyl groups (with respect to decanethiol molecules) onto the surface is about five times lower than the proportion in solution. We have chosen to work with samples prepared from solutions containing $10 \%$ of mercapto-undecanol. This concentration leads to the routine observation of surfaces covered with $2 \%$ of hydroxyl terminated molecules. Interestingly, these molecules are often isolated in crystalline decanethiol domains.

\subsection{STM imaging after esterification reaction}

The strategy of the nanografting is depicted in Fig. 2. Either in a one step process, either in a two steps process, a mixed SAM consisting in decanethiol and mercapto-undecanol is prepared. Then, the Hassner reaction itself is performed, as described above, prior STM observations. STM images (Fig. 3) recorded on such samples show three different kinds of specific sites. Most of the surface is covered by methyl terminated molecules. Such crystalline areas are evidenced in the a region of Fig. 3. We also observe numerous unreacted hydroxyl terminated molecules evidenced in the $\mathrm{b}$ region. This shows that after $2 \mathrm{~h}$ at room temperature, the Hassner reaction is still incomplete. Indeed, similar experiments performed in solution have shown that $12 \mathrm{~h}$ are necessary for a complete reaction as checked by chromatography measurements. Finally, region c evidence a phenyl group grafted on top of a mercapto-undecanol molecule.

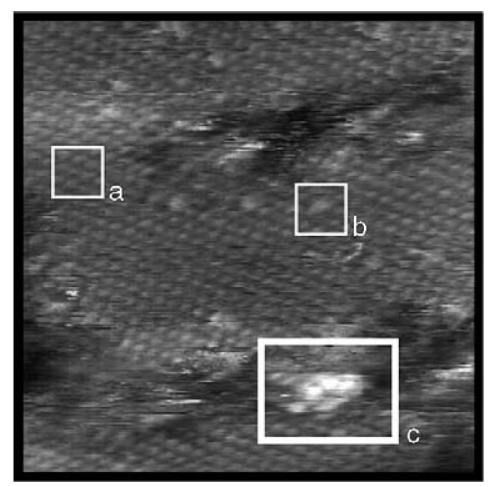

Fig. 3. STM images of mixed SAMs composed of decanethiol and 11-mercapto1-undecanol after chemical reaction between hydroxyl group and benzoic acid. Left: low resolution image, scan size $512 \AA \times 512 \AA, V_{\mathrm{t}}=-900 \mathrm{mV}, I_{\mathrm{t}}=3 \mathrm{pA}$. Right: high resolution image, scan size $160 \AA \times 160 \AA, V_{\mathrm{t}}=500 \mathrm{mV}, I_{\mathrm{t}}=4 \mathrm{pA}$. On the higher resolution image, most of the surface is covered by methyl terminated molecules (region a). We also observe numerous unreacted hydroxyl terminated molecules (b region). Region c evidence a phenyl group grafted on top of a mercapto-undecanol molecule. 
While most of the mercapto-undecanol molecules appear as isolated spots in the mixed SAM, it is very likely that the protrusion of $\mathrm{c}$ type region correspond to a single phenyl group. We assign the apparent lateral extension to the delocalisation of the molecular $\pi$ levels of the benzoic group. Three dimensional (3D) spatially resolved $(x, y, z)$ tunneling spectroscopy of the HOMO-LUMO molecular levels is required to gain a deeper understanding of the data. Such a work is under progress, but is a delicate task while it requires both sub-picoamp currents (highly insulating molecules as stressed above) and high dynamic range of bias voltage (thus UHV operation).

\section{Conclusion}

We have proposed a versatile method to graft carboxylic functionnalized molecules on top of mercapto-undecanol molecules inserted into an alkylthiol SAM. We have shown in this article the results of the chemical reaction between benzoic acid and mercapto-undecanol. As mentionned above, the same procedure can be applied to a wide range of molecular moieties. Such a double barrier tunneling junction where a single molecular group is only weakly coupled to both metallic electrodes, is a promising way for the study of electronic properties of a single molecule, and is a necessary milestone towards the understanding and development of molecular devices.

\section{References}

[1] F. Schreiber, Progr. Surf. Sci. 65 (2000) 151-256.

[2] A. Ulman, Chem. Rev. 96 (1996) 1533-1554.

[3] G.E. Poirier, Chem. Rev. 97 (1997) 1117-1127.

[4] J.P. Folkers, P.E. Laibinis, G.M. Whitesides, Langmuir 8 (1992) 1330-1341.

[5] M.T. Cygan, T.D. Dunbar, J.J. Arnold, L.A. Bumm, N.F. Shedlock, T.P. Burgin, L. Jones II, D.L. Allara, J.M. Tour, P.S. Weiss, J. Am. Chem. Soc. 120 (1998) 2721-2732.

[6] L. Patrone, S. Palacin, J.P. Bourgoin, J. Lagoute, T. Zambelli, S. Gauthier, Chmical Physics, 2002, to be published.

[7] H. Klein, W. Blanc, R. Pierrisnard, C. Fauquet, Ph. Dumas, Eur. Phys. J. B 14 (2000) 371-376.

[8] A. Hassner, V. Alexanian, Tetrahedron Lett. 46 (1978) 44754478.

[9] A. Ulman, An introduction to ultrathin organic films, Academic Press, New York, 1990.

[10] H. Klein, N. Battaglini, B. Bellini, Ph. Dumas, Mater. Sci. Eng. C 19 (2002) 279-283.

[11] M. Sprik, E. Delamarche, B. Michel, Langmuir 10 (1994) 4116-4130.

[12] C.B. Gorman, Y. He, R.L. Caroll, Langmuir 17 (2001) 5324-5328. 